Article

\title{
Induction Heating of Gear Wheels in Consecutive Contour Hardening Process ${ }^{\dagger}$
}

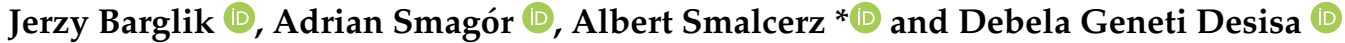

Citation: Barglik, J.; Smagór, A.; Smalcerz, A.; Desisa, D.G. Induction Heating of Gear Wheels in Consecutive Contour Hardening Process. Energies 2021, 14, 3885. https://doi.org/10.3390/en14133885

Academic Editor: William G. Dunford

Received: 31 May 2021

Accepted: 23 June 2021

Published: 28 June 2021

Publisher's Note: MDPI stays neutral with regard to jurisdictional claims in published maps and institutional affiliations.

Copyright: (c) 2021 by the authors. Licensee MDPI, Basel, Switzerland. This article is an open access article distributed under the terms and conditions of the Creative Commons Attribution (CC BY) license (https:// creativecommons.org/licenses/by/ $4.0 /)$.
Department of Industrial Informatics, Silesian University of Technology, 40-019 Katowice, Poland; jerzy.barglik@polsl.pl (J.B.); adrian.smagor@polsl.pl (A.S.); debela.desisa@polsl.pl (D.G.D.)

* Correspondence: albert.smalcerz@polsl.pl; Tel.: +48-32-603-4133

+ This paper is an extended version of our paper published in 19th International Symposium on Electromagnetic Fields in Mechatronics, Electrical and Electronic Engineering (ISEF 2019), Nancy, France, 29-31 August 2019; pp. 1-2.

\begin{abstract}
Induction contour hardening of gear wheels belongs to effective heat treatment technologies especially recommended for high-tech applications in machinery, automotive and aerospace industries. In comparison with long term, energy consuming conventional heat treatment (carburizing and consequent quenching), its main positive features are characterized by high total efficiency, short duration and relatively low energy consumption. However, modeling of the process is relatively complicated. The numerical model should contain both multi-physic and non-linear formulation of the problem. The paper concentrates on the modeling of rapid induction heating being the first stage of the contour induction hardening process which is the time consuming part of the computations. It is taken into consideration that critical temperatures and consequently the hardening temperature are dependent on the velocity of the induction heating. Numerical modeling of coupled non-linear electromagnetic and temperature fields are shortly presented. Investigations are provided for gear wheels made of a special quality steel AISI 300M. In order to evaluate the accuracy of the proposed approach, exemplary computations of the full induction contour hardening process are provided. The exemplary results are compared with the measurements and a satisfactory accordance between them is achieved.
\end{abstract}

Keywords: induction heating; contour hardening; energy efficiency; coupled problems; critical temperatures

\section{Introduction}

Induction Contour Hardening ( $\mathrm{ICH}$ ) of gear wheels is an innovative technological process making it possible to obtain a thin hardened zone along the whole working surface of teeth. The result is a hard microstructure in the contour zone and less-hard microstructure in the transition zone [1,2]. The microstructure of the internal part of the gear wheel remains practically unchanged [3]. Such an environment-friendly heat treatment process is very effective. It is characterized by large productivity and low-specific energy consumption. It is more effective than a long term, energy consuming conventional heat treatment process of gear wheels consisting of carburizing and consequent quenching [4,5]. In many high-tech, industrial applications the crucial quality condition is the fully uniform shape of the hardened contour zone. For the ICH of big gear wheels, such an expected result could be easily achieved by means of Tooth-by-Tooth Induction Hardening (TTIH) method [6,7]. However, for small gear wheels such a method cannot be applied, and it is not so easy to obtain the uniform thickness of the hardened contour zone along the whole tooth by ICH methods. The paper describes the full hardening process. The induction heating stage of the ICH process can be realized mostly in one or two cycles. The one cycle heating process consists of Single Frequency Induction Hardening (SFIH) or, more often, Simultaneous Dual Frequency Induction Hardening (SDFIH) in the medium 
frequency (MF) and high frequency (HF) electromagnetic fields [8-12]. The two cycles process consists of MF induction heating first, followed by immediate shifting of the body between inductors and then finally HF induction heating. The paper deals with this second kind of the approach, which will be later defined as Consecutive Dual Frequency Induction Hardening (CDFIH) [13-15]. In general, the CDFIH process consists of five consecutive stages: MF induction heating, immediate shifting the workpiece between MF and HF inductors, rapid HF induction heating, immediate shifting the gear wheel to the sprayer area, and finally the intensive cooling. Due to a short duration of induction heating, the austenitization process is completely different in comparison with any classical kinds of hardening [16]. Critical temperatures characterizing transformation of any prior microstructure to uniform austenite microstructure are dependent on velocity of induction heating (see Figure 1). In order to determine dependences between critical temperatures and velocity of induction heating the Time-Temperature-Austenitization (TTA) diagram for investigated steel is measured [1]. Austenitization begins at the lower critical temperature $A c_{1}$. When the temperature of the material reaches the upper critical temperature $A c_{3}$ we obtain the austenite microstructure, but it is non-uniform. A fully uniform austenite microstructure is finally obtained only at the modified upper critical temperature $A c_{\mathrm{m}}$. The paper is aimed at modeling the ICH process with a special emphasis put on the induction heating stage. The main goal is formulated as elaboration of the computation method making it possible to obtain an accurate prediction of hardness and microstructure distribution in a hardened element and determination of the shape of the contour zone. However, the modeling of the process is complicated because of the necessity to analyze multi-coupled, non-linear physical fields. In order to reduce the duration of computations, magnetic field quantities are considered in a simplified way as harmonic [7]. However, in order to achieve the expected accuracy of hardness prediction it is crucial to take into consideration:

- The dependence of the critical temperatures for the investigated steel on velocity of induction heating strongly influences upon accurate determination of the hardening temperature;

- The material properties of the investigated steel as non-linear dependences on the temperature;

- The dependence of hardness on the velocity of cooling should be elaborated based upon a set of continuous-cooling-transformation diagrams for the investigated steel starting at different hardening temperatures.

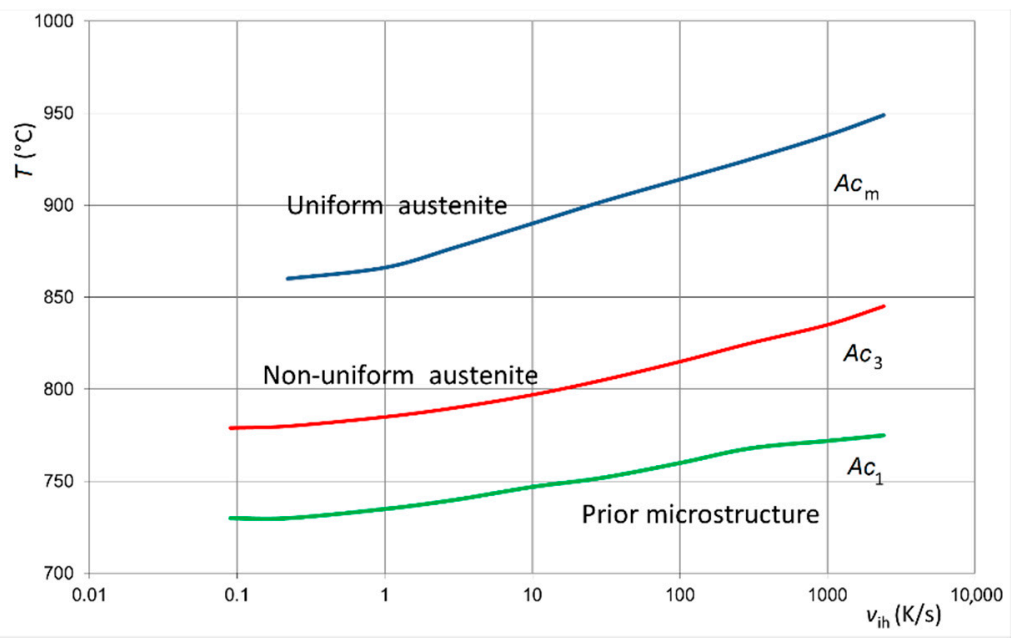

Figure 1. Exemplary dependence of critical temperatures on velocity of induction heating for steel AISI 300M [17]. 
In order to obtain uniform austenite microstructure, the average hardening temperature $T_{\mathrm{h}}$ in the contour zone should be slightly higher than the modified upper critical temperature $A c_{\mathrm{m}}$.

$$
T_{\mathrm{h}} \geq A c_{\mathrm{m}}\left(v_{\mathrm{ih}}\right)=A c_{\mathrm{m}}+\Delta T,
$$

where: $\Delta T=20-30 \mathrm{~K}$.

\section{Mathematical Model of ICH process}

\subsection{Induction Heating for CDFIH Approach}

The mathematical model of the ICH process for electromagnetic computations has been represented by the non-linear partial differential equation for the magnetic vector potential $A$ [7]:

$$
\operatorname{curl}\left(\frac{1}{\mu} \cdot \operatorname{curl} A\right)+\gamma \frac{\partial A}{\partial t}=J_{S},
$$

where: $\mu$-denotes the magnetic permeability, $\gamma$-the electric conductivity, $J_{S}$-vector of field current density.

The solving of the Equation (2) in the 3D configuration has to be simplified assuming that the magnetic field quantities are harmonic [18]. The main reason of such a simplification is a distinct disproportion between period of field current and time constant of thermal phenomena. Equation (2) is transformed to the following Equation (3) for phasor of the magnetic vector potential $\underline{A}$ :

$$
\operatorname{curl}(\operatorname{curl} \underline{\boldsymbol{A}})+\mathrm{j} \cdot \omega \gamma \mu \underline{\boldsymbol{A}}=\mu \boldsymbol{J}_{S^{\prime}}
$$

where: $\mathrm{j}$ denotes the imaginary unity and $\omega$-angular frequency.

The continuous mathematical model of the ICH process for temperature computations has been represented by the non-linear Fourier-Kirchhoff Equation [19]:

$$
\operatorname{div}(\lambda \cdot \operatorname{grad} T)-\rho \cdot c_{p} \cdot \frac{\partial T}{\partial t}=-p_{\mathrm{V}}
$$

where: $\lambda$-thermal conductivity, $\rho$-specific mass, $c_{p}$-specific heat at constant pressure, $p_{\mathrm{V}}$ volumetric power density as external heat source taken from electromagnetic computations.

The block diagram representing mathematical model of induction heating is presented in Figure 2.

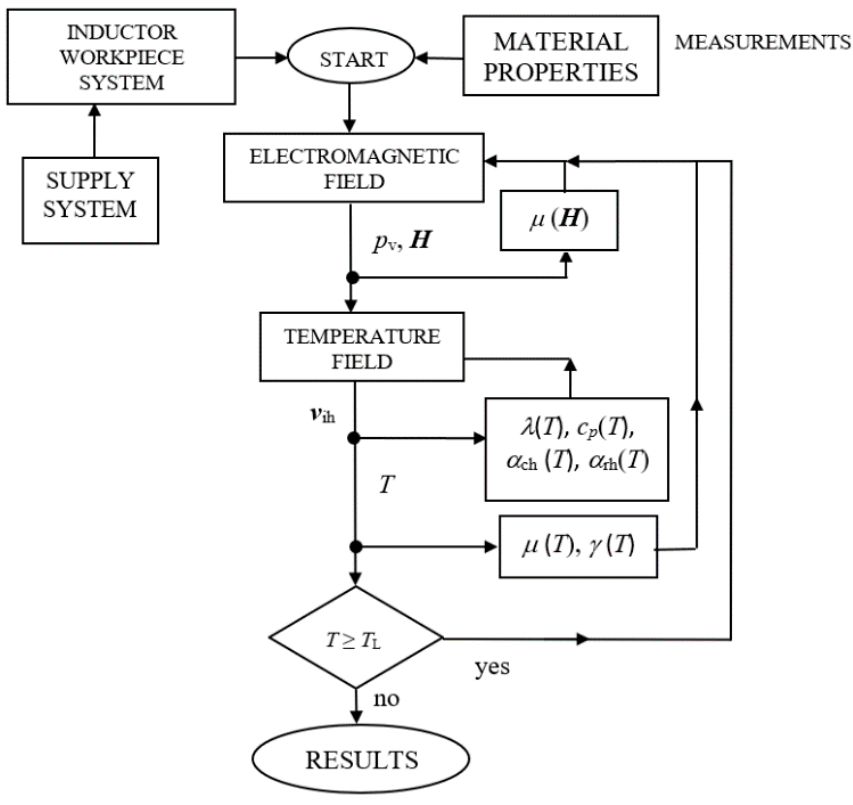

Figure 2. Mathematical model of induction heating. 
Input data for electromagnetic computations contain:

- $\quad$ Electric supply parameters: Inductor current or voltage and its frequency;

- Geometry of inductor-gear wheel system;

- Material properties of investigated steel and their dependences on field quantities (magnetic field intensity $\boldsymbol{H}$, temperature $T$ );

Average volumetric power density $p_{\mathrm{v}}$ consists of two components connected respectively with Joule $p_{\mathrm{J}}$ and hysteresis $p_{\mathrm{H}}$ phenomena:

$$
p_{\mathrm{V}}=p_{\mathrm{J}}+p_{\mathrm{H}}=\gamma \cdot|\underline{\boldsymbol{E}}|^{2}+\mu \cdot f \cdot|\underline{\boldsymbol{H}}|^{2}
$$

where: $\underline{E}$-phasor of electric field density, $f$-frequency of field current, $\underline{H}$-phasor of magnetic field density.

However, for the analyzed case the hysteresis components are significantly smaller than the Joule phenomenon one and it could be neglected [20]. Finally volumetric power density has only one component and it depends on induced current density $\underline{I}_{\text {ind }}$ :

$$
p_{\mathrm{V}}=\gamma \cdot|\underline{E}|^{2}=\frac{\left|\underline{J}_{\text {ind }}\right|^{2}}{\gamma} \quad \underline{J}_{\text {ind }}=-\mathrm{j} \cdot \omega \cdot \gamma \cdot \underline{A},
$$

The magnetic permeability of the investigated steel AISI 300M and other ferromagnetic parts like magnetic core depends on magnetic field density and temperature. In order to take into account a non-linear dependence of magnetic permeability on magnetic field intensity, its local values in each cell of the discretization mesh are determined. Dependence of the magnetic permeability on temperature is considered by means of ((Equations (7) and (8)):

$$
\begin{gathered}
\mu(\underline{\boldsymbol{H}}, T)=\mu_{0}\left[1+\left(\mu_{\mathrm{r}}\left(\underline{\boldsymbol{H}}, T_{0}\right)-1\right) \cdot f(T)\right], \\
f(T)=\left\{\begin{array}{c}
1-\mathrm{e}^{\frac{T-T_{\mathrm{C}}}{\mathrm{C}}} \text { for }<T_{\mathrm{C}}, \\
\mathrm{e}^{\frac{10\left(T_{\mathrm{C}}-T\right)}{\mathrm{C}}} \text { for } T \approx T_{\mathrm{C}}
\end{array}\right.
\end{gathered}
$$

where: $\mu_{0}$-the magnetic permeability of vacuum, $\mu_{\mathrm{r}}$-relative magnetic permeability, $T_{0}$-ambient temperature, $T_{\mathrm{C}}$-temperature of the Curie point, $C$ - constant dependent on kind of steel.

For ambient temperature, the magnetic permeability is determined by measurements. However, a dependence of the magnetic permeability of the investigated steel on the field current frequency is neglected [20]. The non-linear dependence of the electric conductivity on temperature is taken into consideration.

Input data for temperature computations contain:

- Distribution of volumetric power density in the heated element;

- Dependence of specific heat, thermal conductivity, convection and radiation heat transfer coefficients on temperature;

- Time-temperature-austenitization diagram for the investigated steel;

- Expected hardening temperature guaranteeing uniform austenite microstructure.

For temperature field calculations convection and radiation heat transfer phenomena are considered. The boundary condition along the external surface of the workpiece is given in the Equation (9):

$$
-\lambda \frac{\partial T}{\partial n}=\alpha_{\mathrm{ch}}\left(T-T_{\mathrm{ac}}\right)+\sigma_{0} \cdot \varepsilon \cdot\left(T^{4}-T_{\mathrm{ar}}^{4}\right),
$$

where: $n$ denotes outwards normal to the external border of the domain, $\alpha_{\mathrm{ch}}-$ convection heat transfer coefficient (heating), $T_{\mathrm{ac}}, T_{\mathrm{ar}}$-temperature of convection and radiation environment respectively, $\sigma_{0}$-Boltzmann constant, $\varepsilon$ - total emissivity of radiation surface. 
Analysis of the multiple reflection phenomena required special numerical procedure [21]. For this problem they are neglected. Taking into account non-linear dependences of material properties and heat transfer parameters on temperature makes possible to avoid inaccuracy in modeling which could reach an order even of about $100 \mathrm{~K}$ [22-24]. As a result of temperature computations, we obtain temperature as a function of time and velocity of induction heating. Computations are provided by means of the Flux 3D software for hard coupled electromagnetic and temperature field during induction heating and some single-owned procedures elaborated by the authors [25]. For CDFIH process modeling of induction heating stage consists of three consecutive stages:

- $\quad$ MF heating-time $t_{\mathrm{MF}}$;

- $\quad$ Short break for shifting workpiece between inductors-time $t_{\mathrm{b}}$;

- HF heating-time $t_{\mathrm{HF}}$.

Total time of induction heating:

$$
t_{\mathrm{ih}}=t_{\mathrm{MF}}+t_{\mathrm{b}}+t_{\mathrm{HF}}
$$

MF heating terminates when average temperature in contour zone reaches the level of the lower critical temperature $A c_{1}\left(v_{\text {ih }}\right)$

$$
\left.T_{\mathrm{av}}\right|_{t=t_{\mathrm{MF}}}=T_{\mathrm{L}} \approx A c_{1}\left(v_{\mathrm{ih}}\right),
$$

Computations of HF induction heating terminate when the average hardening temperature exceeds the modified critical temperature $A c_{\mathrm{m}}\left(v_{\mathrm{ih}}\right)$.

$$
\left.T_{\mathrm{av}}\right|_{t=t_{\mathrm{ih}}}=T_{\mathrm{h}} \geq A c_{\mathrm{m}}\left(v_{\mathrm{ih}}\right),
$$

2.2. Cooling

Input data for cooling computations contain:

- Geometry of sprayer-gear wheel system;

- Cooling parameters (parameters of cooling medium, its pressure, flow-rate and temperature);

- Initial temperature distribution in the workpiece;

- $\quad$ CCT (Continuous-Cooling-Transformation) diagram for investigated steel;

- Convection heating transfer coefficient for intensive cooling.

Block diagram of numerical model for cooling is presented in Figure 3.

Time of a break between heating and cooling could be neglected because the cooling practically starts immediately when the HF inductor is switched off. Temperature field is determined based upon Equation (4) $\left(p_{\mathrm{V}}=0\right)$. Radiation is neglected. Convection heat transfer coefficient for cooling $\alpha_{\mathrm{cc}}$ depends on temperature, but in practice it is analyzed in a simplified way by putting different values on all boundaries of the domain. For the cooling stage as well the Flux 3D software for temperature field coupled with the modified QT steel supported by several own numerical procedures for hardness and microstructure fields are applied [26]. A special numerical procedure making possible to couple directly Flux 3D and QT steel codes is elaborated. Taking into consideration that when the induction heating is terminated, the non-uniform temperature within the tooth, highest at the surface and lower inside the material is observed. The velocity of cooling $v_{\mathrm{c}}$ is determined based upon several measured Continuous-Cooling-Transformation (CCT) diagrams starting of different hardening temperatures $T_{\mathrm{h}}$. For the analyzed problem hardening temperature $T_{\mathrm{h}}$ changes between $\left(850-1050{ }^{\circ} \mathrm{C}\right)$. Based upon these diagrams, dependences of the hardness on the velocity of cooling in different points of tooth are elaborated. Exemplary dependence of hardness on velocity of cooling for the hardening temperature $T_{\mathrm{h}}=960^{\circ} \mathrm{C}$ is presented in Figure 4. 


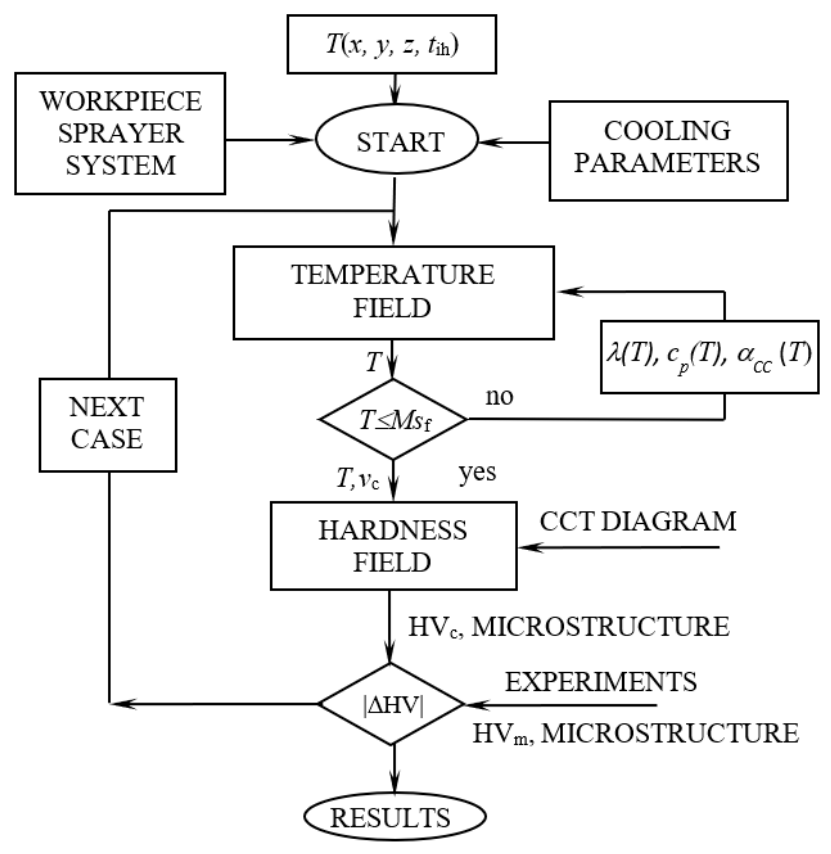

Figure 3. Mathematical model of intensive cooling.

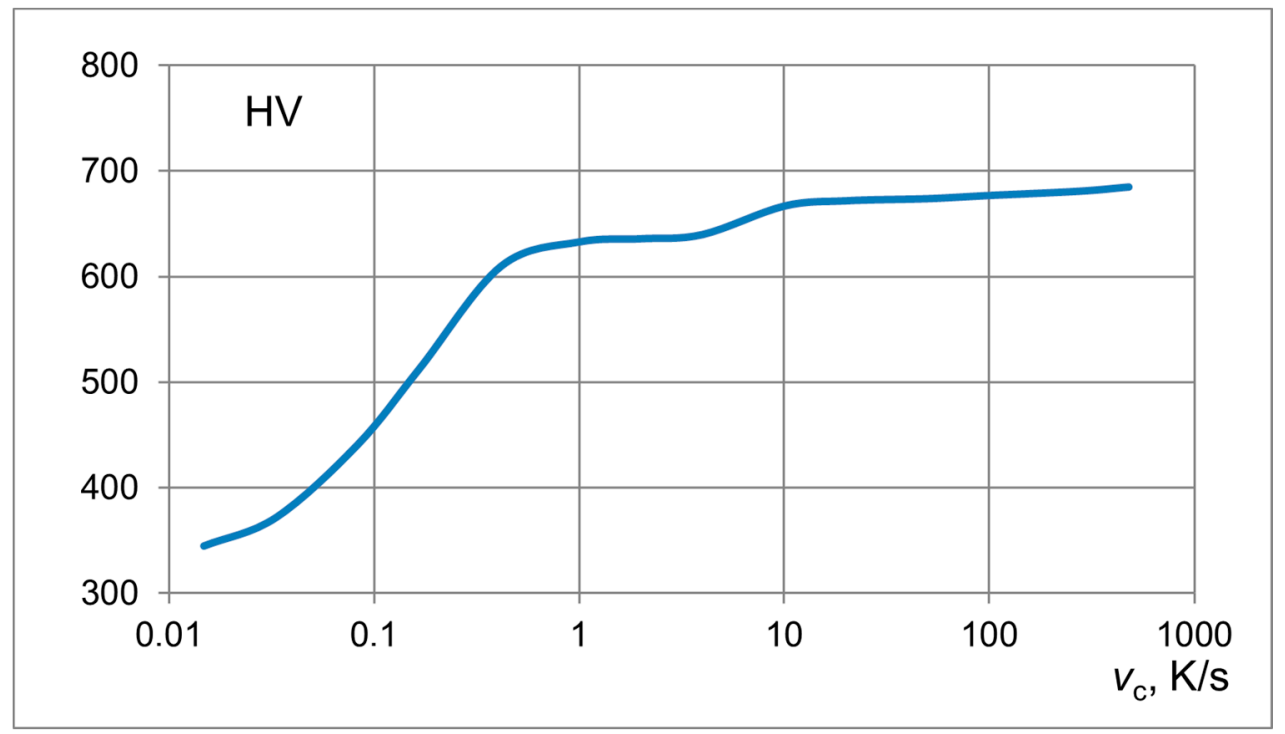

Figure 4. Hardness as a function of velocity of cooling, steel AISI 300M based upon measured CCT diagrams (own source).

Finally, hardness and microstructure distributions within $\frac{1}{4}$ part of the tooth are determined and a shape of the hardened contour zone is achieved. Computations are compared with measurements and if a condition of accordance is not satisfied, the next case with modified parameters is computed.

\section{Formulation of the Problem}

Let us consider an example of the CDFIH process provided for small gear wheels made of the special quality steel AISI 300M (AMS 6419) [17]. Its chemical composition is presented in Table 1. 
Table 1. Chemical composition of alloy additions steel AISI 300M.

\begin{tabular}{cccccccc}
\hline Element & $\mathbf{C}$ & $\mathbf{S i}$ & $\mathbf{M n}$ & $\mathbf{C r}$ & $\mathbf{N i}$ & Mo & Fe \\
\hline Mass, $\%$ & 0.41 & 1.63 & 0.83 & 0.83 & 1.91 & 0.41 & 95 \\
\hline
\end{tabular}

Its prior microstructure consists of the tempered martensite with some single particles of tempered bainite. Phenomena connected with reverse transformation from the tempered martensite to the uniform austenite are described for instance in [27]. Dependence of modified upper critical temperature for steel AISI 300M is shown in Table 2 (see Figure 1).

Table 2. Dependence of modified upper critical temperature $A c_{\mathrm{m}}$ on velocity of induction heating [17].

\begin{tabular}{cccccccc}
\hline$v_{\text {ih }}, \mathrm{K} / \mathrm{s}$ & 0.1 & 1 & 10 & 100 & 200 & 500 & 1000 \\
\hline$A c_{\mathrm{m}},{ }^{\circ} \mathrm{C}$ & 887 & 899 & 924 & 955 & 985 & 1030 & 1055 \\
\hline
\end{tabular}

Material properties for steel AISI 300M determined by measurements are depicted in Figures 5-7 respectively.

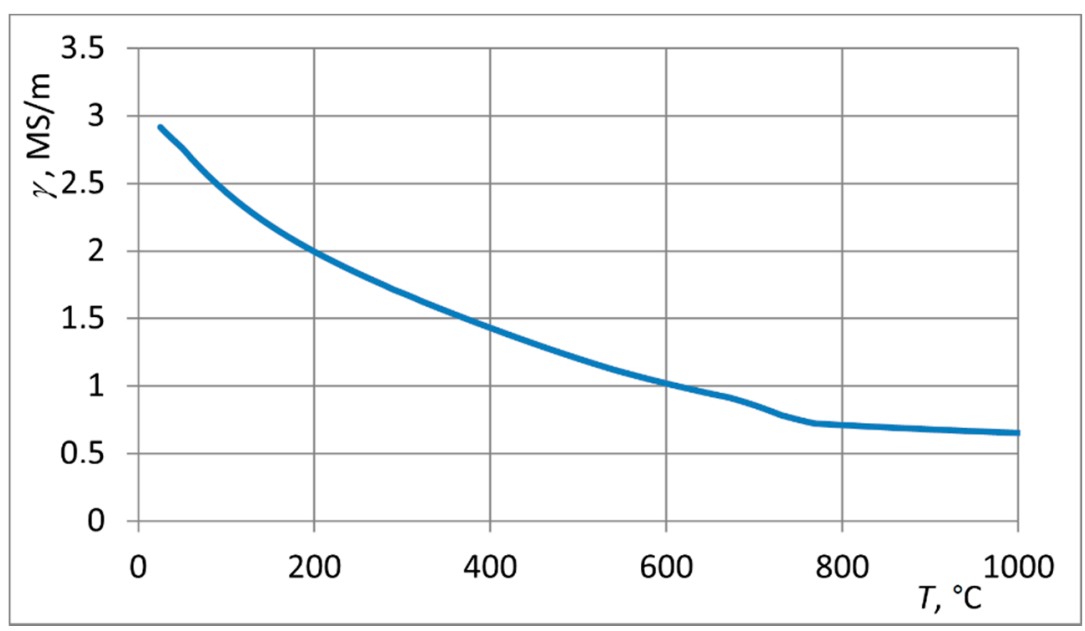

Figure 5. Dependence of electric conductivity on temperature, based upon measurements (own source).

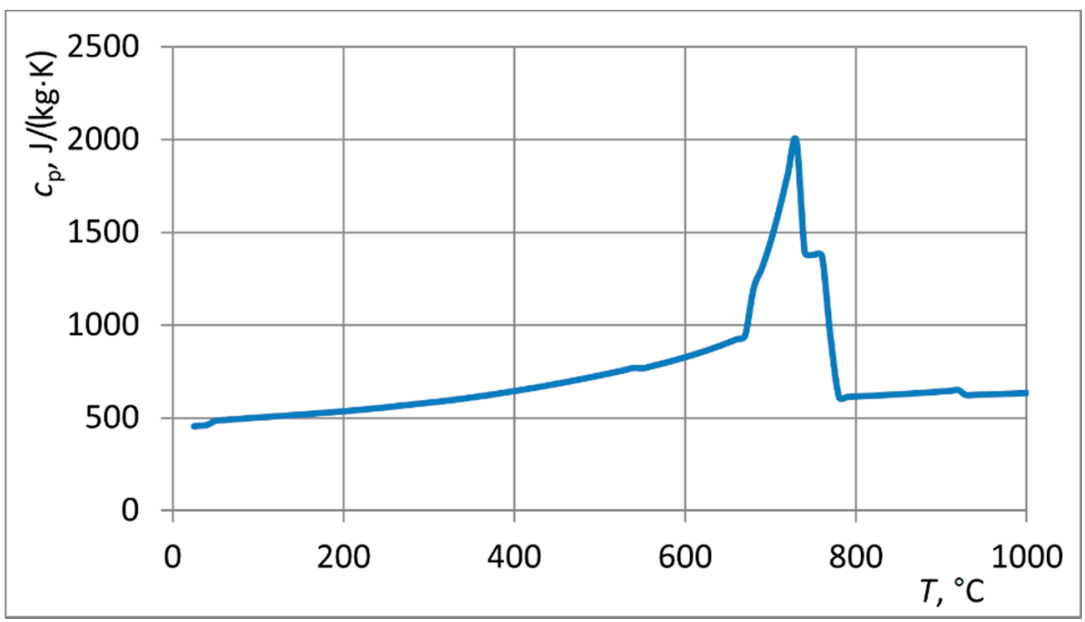

Figure 6. Dependence of specific heat on temperature-based upon measurements (own source). 


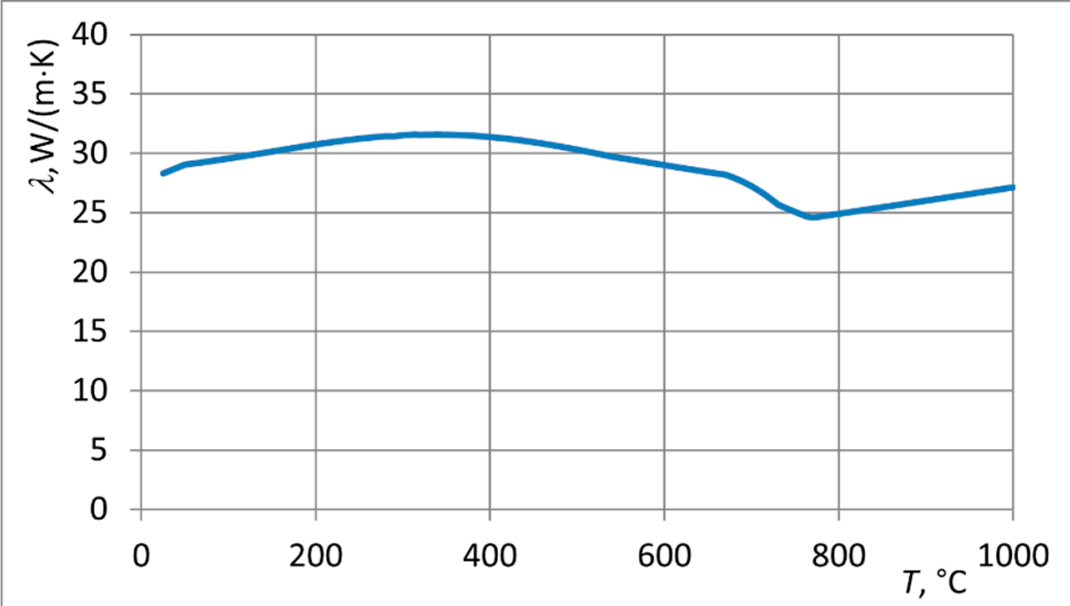

Figure 7. Dependence of thermal conductivity on temperature-based upon measurements (own source).

Main dimensions and parameters of the inductor gear wheel systems are as follow [28]:

- Gear wheel: teeth number-16, width of the tooth ring-6 $\mathrm{mm}$, top diameter$35.6 \mathrm{~mm}$, root diameter $-26.9 \mathrm{~mm}$, hole diameter $-16 \mathrm{~mm}$.

- MF inductor: external diameter $-54 \mathrm{~mm}$, internal diameter $-39.5 \mathrm{~mm}$, height $-7 \mathrm{~mm}$.

- HF inductor: external diameter $-61 \mathrm{~mm}$, internal diameter $-39.5 \mathrm{~mm}$, height $-21 \mathrm{~mm}$, flux concentrator made of Fluxtrol 50: its external diameter $-81.5 \mathrm{~mm}$, its internal diameter $39 \mathrm{~mm}$, thickness of upper and lower cylinder $-5 \mathrm{~mm}$.

- Sprayer: distance between inductor and sprayer-20 mm, external diameter- $85 \mathrm{~mm}$, internal diameter- $61 \mathrm{~mm}$.

Several computations are provided in order to make a correct selection of the process parameters. Due to symmetry and periodicity of the system computations are provided for $\frac{1}{4}$ part of tooth only. Based upon these computations following parameters for experiments of the CDFIH process are finally determined:

- MF induction heating: current-1450 A, heating time $-4.4 \mathrm{~s}$, frequency-36 kHz.

- Break between MF and HF heating: $-0.1 \mathrm{~s}$.

- HF induction heating: current-520 A, time-0.4 s, frequency-242 kHz.

- Parameters of cooling: quenchant-polymer solution Aqua Quench 140, concentration$10 \%$, temperature $-25^{\circ} \mathrm{C}$, pressure $-89 \mathrm{kPa}$, flow-rate $-2 \cdot 10^{-5} \mathrm{~m}^{3} / \mathrm{s}$, convection heat transfer coefficient at external surface- $400 \mathrm{~W} /\left(\mathrm{m}^{2} \cdot \mathrm{K}\right)$.

- Heating rate and critical temperatures: velocity of induction heating- $205 \mathrm{~K} / \mathrm{s}$, modified upper critical temperature $-993^{\circ} \mathrm{C}$, hardening temperature- $1010{ }^{\circ} \mathrm{C}$.

Experiments are provided at the specialized laboratory stand located in the Silesian University of Technology in Katowice [29]. Configuration of inductors-sprayer-gear wheel systems is shown in Figure 8. 


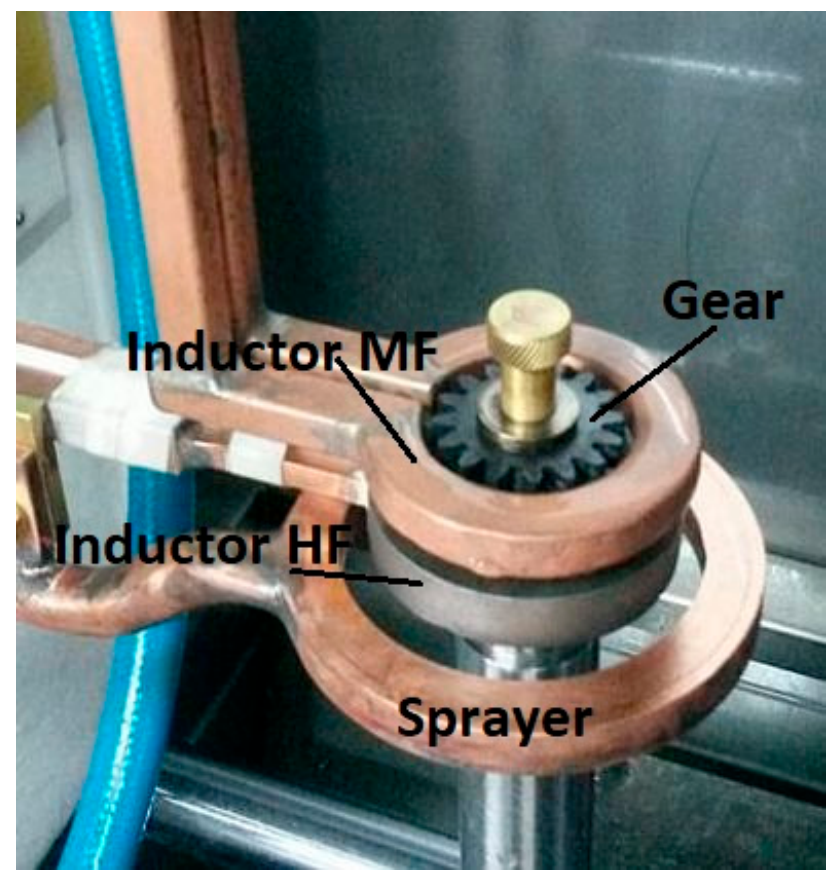

Figure 8. Configuration of the CDFIH system.

Both inductors have a ring shape. They are water cooled. The HF inductor is equipped in the magnetic flux concentrator made of Fluxtrol 50 [30].

\section{Results and Discussion}

Comparison between computations and measurements is done for hardness distribution along the line A ... G at the working surface of the tooth, while point $A$ is located in the root and point $G$ in the top of the tooth (see Figures 9 and 10). Measurements of hardness distribution on the cross-section of studied gear wheels are carried out by Vickers method at load 5N (HV0,5) using microhardness tester Future-Tech FM 700 [31]. Microstructure observations are provided at micro-sections taken from slices of gear wheels by means of microscope Olympus type GX51.

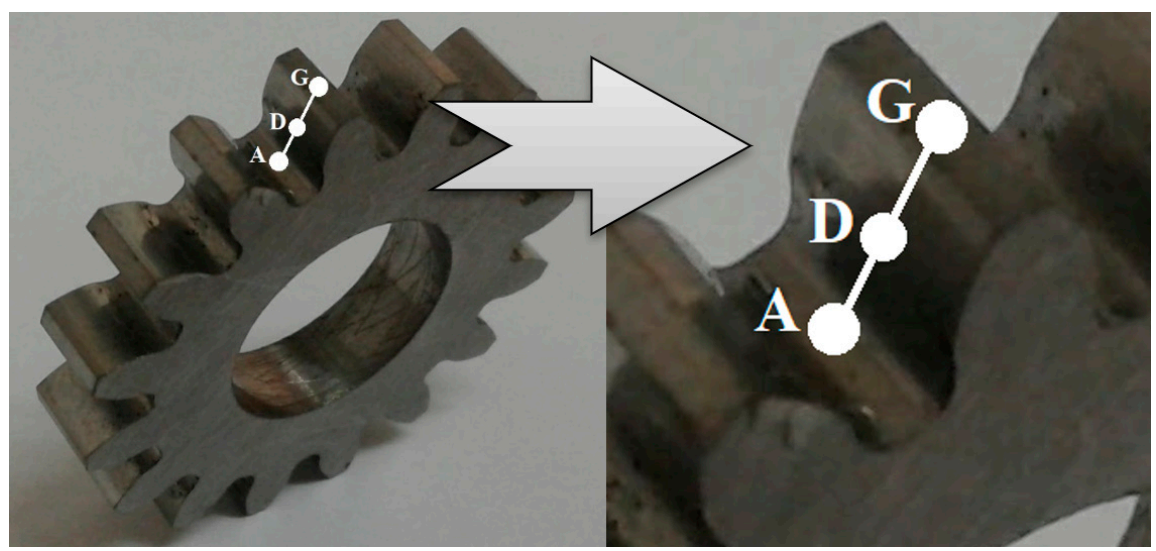

Figure 9. Working surface (body) of the tooth with depicted location of points A...D...G. 


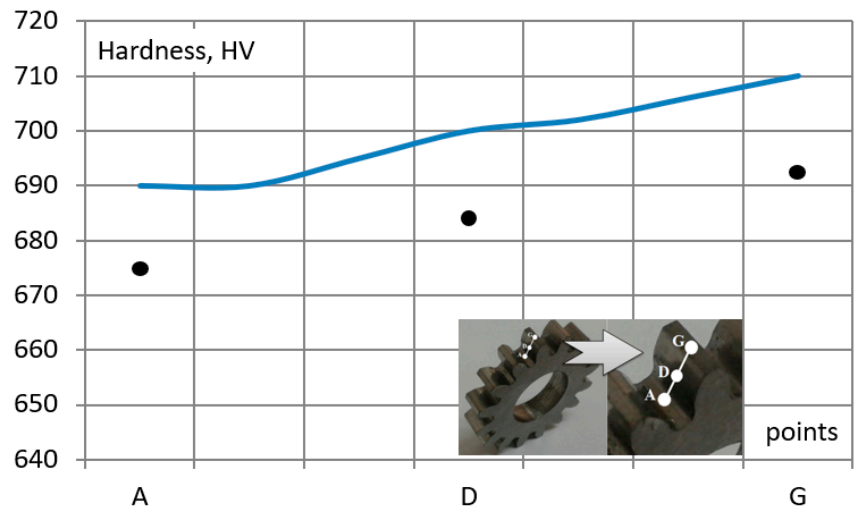

Figure 10. Distribution of hardness along the working surface of the tooth: ——computations (line A ... G); ••-measurements in points A, D, G.

The difference between computations and measurements reaches a level of $20 \mathrm{HV}$. It is almost the same difference along the whole line A ... G. For both computations and measurements the difference between hardness at point A (root) and point G (top) is about $20 \mathrm{HV}$. Such accuracy matches practical requirements. However, another, but more serious problem is the shape of the contour hardened zone. For many advanced applications there is a request for the shape of contour pattern which should be as uniform as possible.

Let us define the Surface Depth Hardening coefficient $(S D H)$ describing a thickness of the contour layer defined as a distance from the surface inside the material to a point in which the hardness decreases to the value of $80 \%$ of hardness on the surface. The dependence of hardness on distance directed from surface inside the material for points: G (top), A (root) and D (middle part of the tooth body) are presented in Figures 11-13 respectively.

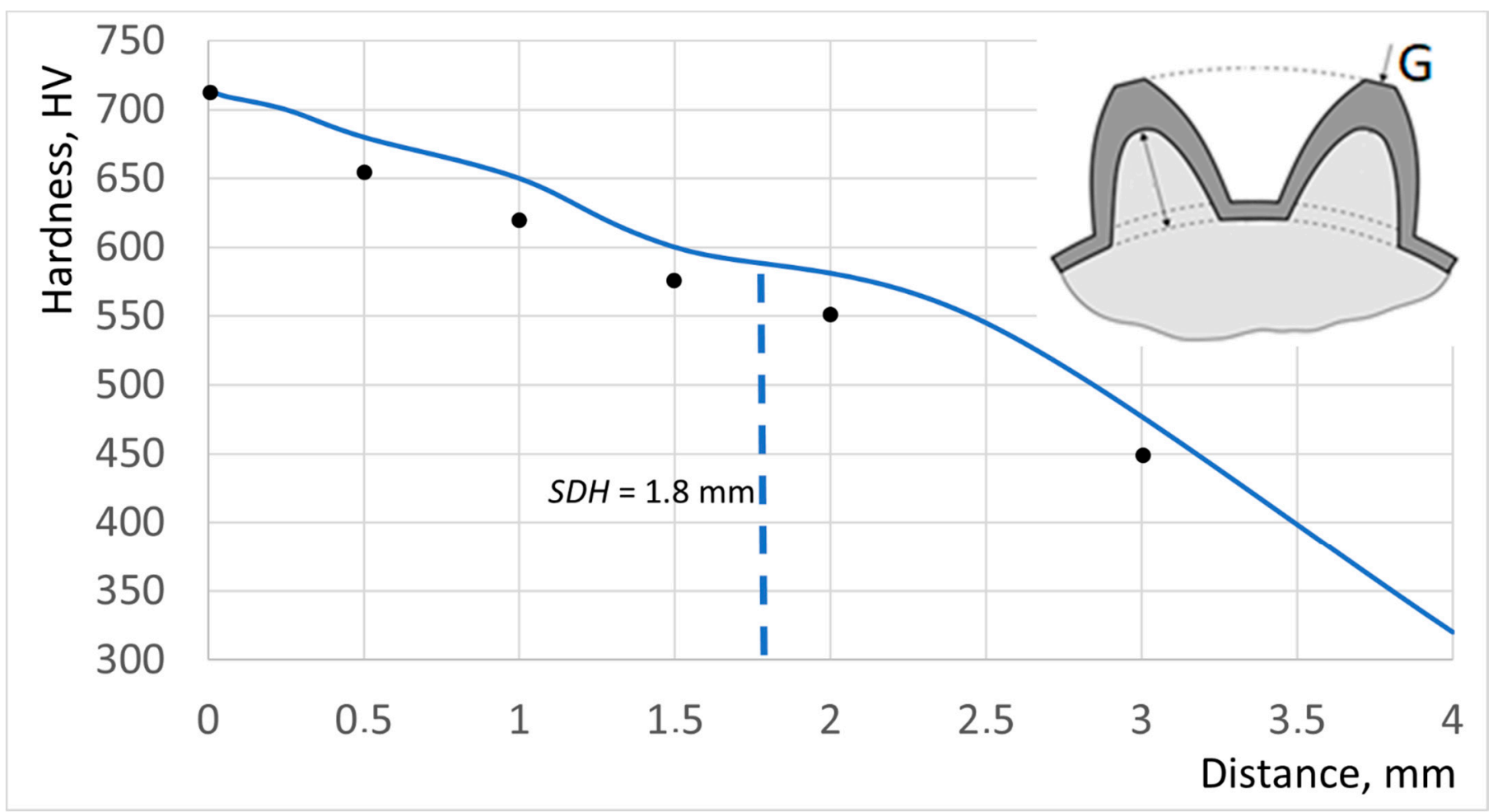

Figure 11. Dependence of hardness on distance from surface inside the material in point G located at the top of the tooth:

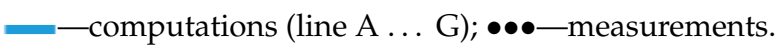




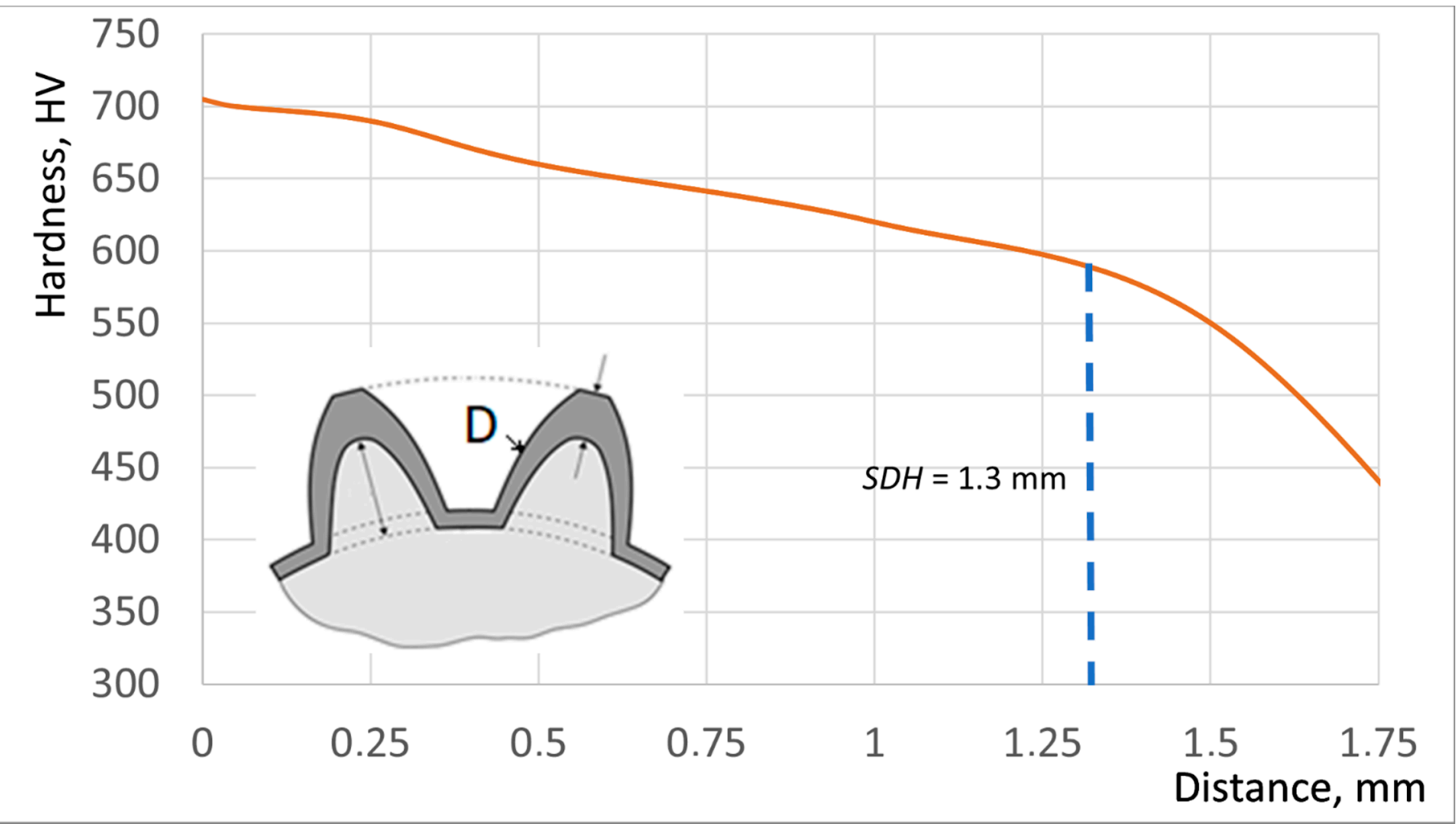

Figure 12. Dependence of computed hardness on distance from surface inside the material in point $\mathrm{D}$ located in a middle part of the tooth body.

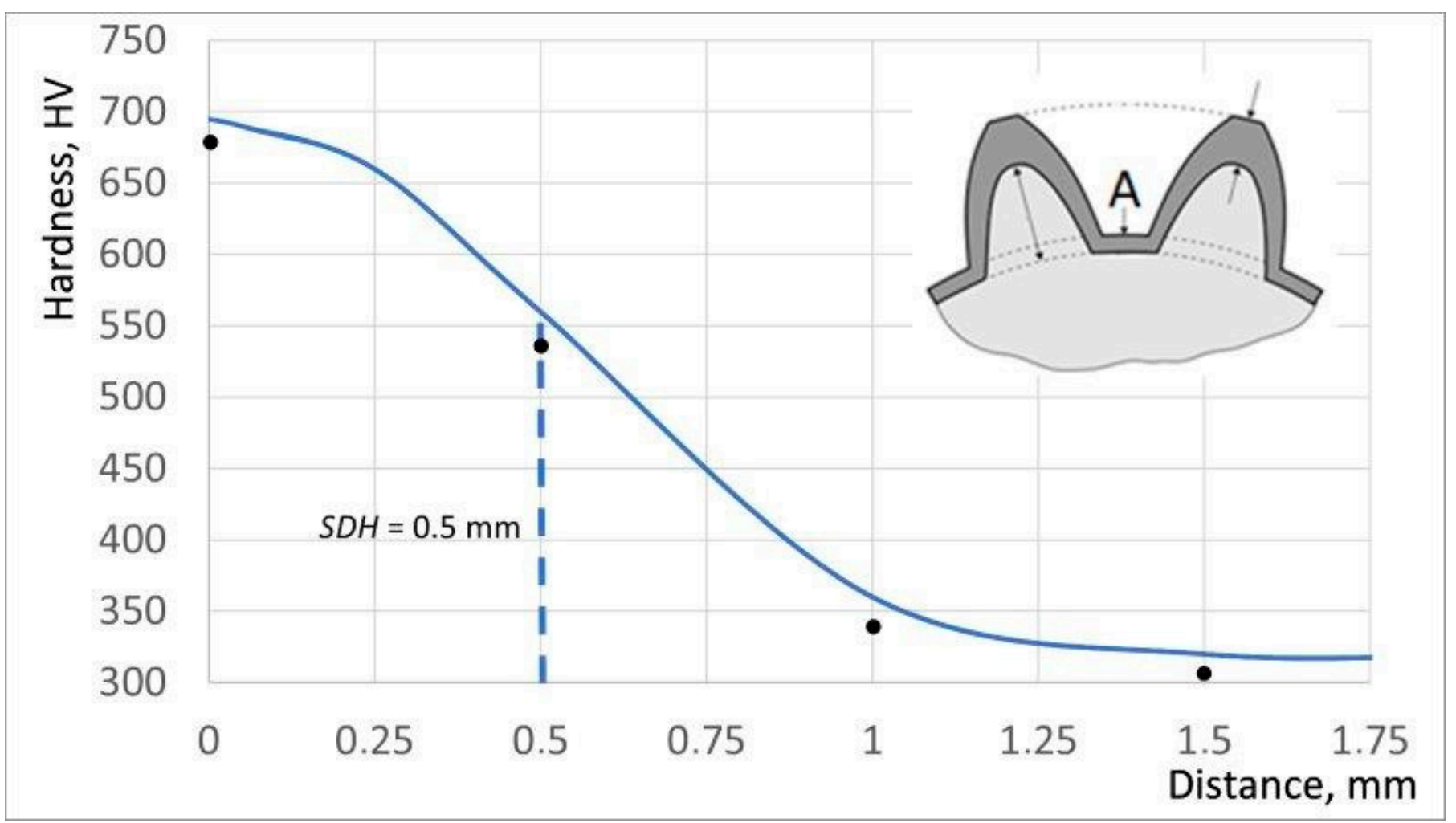

Figure 13. Dependence of hardness on distance from surface inside the material in point A located at the root of the tooth:

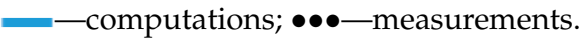


For point $\mathrm{G}$ at top $S D H=1.8 \mathrm{~mm}$ and thickness of the hardened zone is the biggest. A minimal value of the $S D H$ coefficient is noticed in point A at the root $(S D H=0.5 \mathrm{~mm})$. Distribution of the $S D H$ coefficient along the line A ... G is presented in Figure 14 .

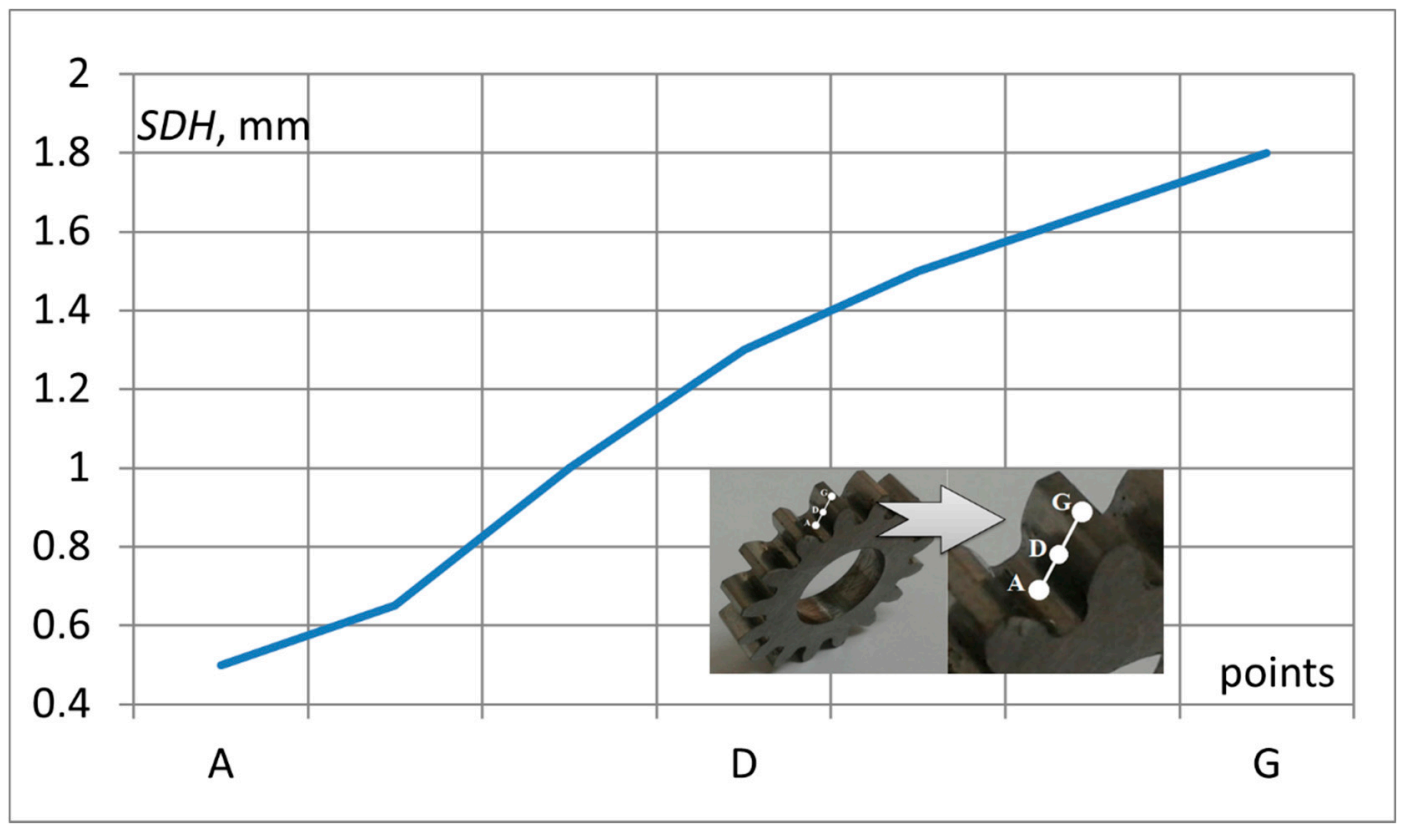

Figure 14. Distribution of the $S D H$ coefficient along the line A ... G.

The obtained SDH coefficient changes from $1.8 \mathrm{~mm}$ at the top of the tooth to $0.5 \mathrm{~mm}$ at the root. It means a reasonable (less than $5 \%$ ) difference between computations and measurements. Microstructure of the contour zone creates acicular martensite with some single particles of bainite (Figure 15).

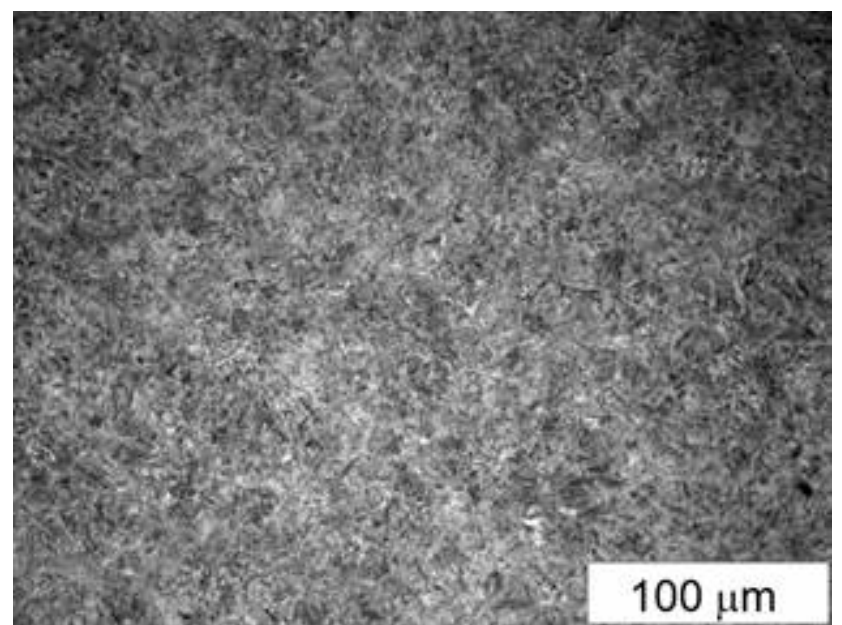

Figure 15. Microstructure of the contour zone. Mag $\times$ 500. Acicular martensite.

Inside the material, if a distance from the surface is higher than $4 \mathrm{~mm}$ the hardness decreases to the value of $320 \mathrm{HV}$ which means that, as expected, the prior microstructure of tempered martensite in the core of the gear wheel is unchanged. Results presented and described in the paper confirm that the proposed method makes it possible to achieve the expected accuracy of hardness prediction. The presented calculation method makes it possible to achieve reasonable accordance between computations and measurements. Another problem is the shape of the contour zone. For its description, the $S D H$ coefficient is used. The calculated 
non-uniform shape of the contour zone is validated by the measurements. In order to achieve a more uniform shape of the contour hardened zone it is necessary to decrease heating time and increase the delivered power. Another solution is to apply the SDFIH process, and in this case short heating duration and large delivery of power are expected.

\section{Conclusions}

The CDFIH process described in the paper is successfully applied for the energyefficient contour hardening of gear wheels. The proposed mathematical model could be the effective tool for the design of such processes. It makes it possible to predict hardness and microstructure distributions with a reasonable accuracy of about $20 \mathrm{HV}$. In order to minimize the computation time, magnetic field quantities are considered in a simplified way as harmonic. The model should contain additional numerical procedures based upon specialized measurements for the investigated steel (TTA and CCT diagrams), making it possible to determine hardening temperature as a function of velocity of induction heating and hardness as a function of velocity of cooling and hardening temperature. The next paper in this area will be aimed at improvement of the described process in order to obtain the uniform shape of the contour zone.

Author Contributions: Conceptualization, J.B.; methodology, A.S. (Albert Smalcerz); software, D.G.D.; validation, A.S. (Albert Smalcerz), J.B. and A.S. (Adrian Smagór); formal analysis, A.S. (Albert Smalcerz); investigation, A.S. (Adrian Smagór); resources, D.G.D.; data curation, A.S. (Adrian Smagór); writing-original draft preparation, J.B.; writing-review and editing, A.S. (Albert Smalcerz); visualization, A.S. (Adrian Smagór); supervision, J.B.; project administration, A.S. (Albert Smalcerz); funding acquisition, A.S. (Albert Smalcerz) All authors have read and agreed to the published version of the manuscript.

Funding: This research was funded by National Centre for Research and Development, grant number PBS2/A5/41/2014 This research was supported by the Silesian University of Technology, grants No. 11/040/BK_21/0023 and 11/040/BKM21/0025.

Institutional Review Board Statement: Not applicable.

Informed Consent Statement: Not applicable.

Data Availability Statement: The data that support the findings of this study are available from the corresponding author upon reasonable request.

Conflicts of Interest: The authors declare no conflict of interest.

\section{References}

1. Rudnev, V.; Totten, G. Induction Heating and Heat Treatment 4C; ASM International: Materials Park, OH, USA, 2014.

2. Jones, K.T.; Newsome, M.; Carter, D. Gas carburizing vs. contour induction hardening on bevel gears. Gear Solut. $2010,8,38-54$.

3. Chatterjee, M. Comparative Study of Carburizing vs. Induction Hardening of Gear Wheels. 2003. Available online: https: / / www.heattreattoday.com/processes/carburizing/carburizing-technical-content/comparative-study-of-carburizingvs-induction-hardening-of-gears/ (accessed on 15 May 2021).

4. Schwenck, M.; Schwenck, W. Substitution of case hardening gearbox components in the automotive as well as aeronautical industry through contour induction hardening. In Proceedings of the International Conference on Heating by Electromagnetic Sources, HES-07, Padova, Italy, 20-22 June 2007; pp. 175-182.

5. Rudnev, V. Induction hardening of gear wheels and critical components Part 1. Gear Technol. 2008, 1, $58-63$.

6. Rudnev, V.; Loveless, D.; Cook, R. Handbook of Induction Heating; CRC Press: London, UK; Taylor and Francis Group: Abingdon, UK, 2018.

7. Lupi, S. Fundamentals of Electroheat, Electrical Technologies for Process Heating; Springer: Cham, Switzerland, 2017.

8. Rudnev, V.; Loveless, D.; Cook, R.; Black, M. Induction Hardening of Gear. Heat Treat. Met. 2004, 1, 11-15.

9. Pleshcheva, Y.; Baldan, N.; Popov, A.; Nikanorov, A.; Rapaport, E.; Nacke, B. Effective methods for optimal design of induction coils on example of surface hardening. COMPEL Int. J. Comput. Math. Electr. Electron. Eng. 2019, 39, 90-99.

10. Kwang-Hyung, C.; Chang-Tae, J.; Rae-Young, K. Analysis and evaluation of WBG power device in high frequency induction heating application. Energies 2020, 13, 5351.

11. Goldstein, R.; Nemkov, V. Design Principles for Induction Heating and Hardening. In Handbook of Metallurgical Process Design; Marcel Dekker: New York, NY, USA, 2004; pp. 591-640. 
12. Szychta, E.; Szychta, L. Comparative Analysis of Effectiveness of Resistance and Induction Turnout Heating. Energies 2020, 13, 5262. [CrossRef]

13. Rudnev, V. Induction hardening of gear wheels and critical components Part 2. Gear Technol. 2008, 2, 47-53.

14. Buglaliero, N.; Zimmerman, C.; Richardson, S.; Perkins, R.; McCurdy, D.; Giessel, B. Heat Treatment Processes for Gear WheelsGear Solutions. 2010. Available online: https://gearsolutions.com/features/heat-treat-processes-for-gears/ (accessed on 15 May 2021).

15. Spezzapria, M.; Forzan, M.; Dughiero, F. Numerical Simulation of Solid-Solid Phase Transformations During Induction Hardening. IEEE Trans. Magn. 2016, 52, 740-743. [CrossRef]

16. Barglik, J. Mathematical modelling of induction surface hardening. COMPEL Int. J. Comput. Math. Electr. Electron. Eng. 2016, 35, 1403-1417. [CrossRef]

17. Barglik, J. Induction contour hardening of gear wheels made of steel 300M. IOP Conf. Ser. Mater. Sci. Eng. 2018, 424, 012062. [CrossRef]

18. Lupi, S.; Forzan, M.; Alifierov, A. Induction and Direct Resistance Heating: Theory and Numerical Modelling; Springer: Berlin/Heidelberg, Germany, 2015.

19. Holman, P. Heat Transfer; Mc Graw Hill: New York, NY, USA, 2009.

20. Barglik, J.; Smalcerz, A. Influence of the magnetic permeability on modelling of induction surface hardening. COMPEL Int. J. Comput. Math. Electr. Electron. Eng. 2017, 36, 555-564. [CrossRef]

21. Barglik, J.; Czerwiński, M.; Hering, M.; Wesołowski, M. Radiation in Modelling of Induction Heating Systems; IOS Press: Amsterdam, The Netherlands, 2008; pp. 202-211.

22. Barglik, J.; Smalcerz, A.; Przylucki, R.; Dolezel, I. 3D modeling of induction hardening of gear wheels. J. Comput. Appl. Math. 2014, 270, 231-240. [CrossRef]

23. Zgraja, J.; Lisowski, G.; Kucharski, J. Autonomous Energy Matching Control in an LLC Induction Heating Generator. Energies 2020, 13, 1860. [CrossRef]

24. Barglik, J. Induction hardening of steel elements with complex shapes. Przeglad Elektrotechniczny 2018, 94, 51-54. [CrossRef]

25. WinSite. Cedrat Flux Software. Available online: https://www.winsite.com/cedrat/cedrat+flux/ (accessed on 15 May 2021).

26. ITA Technology and Software. QTSteel Software. Available online: http://www.ita-tech.cz/en/products-services/heattreatment/software-qtsteel (accessed on 15 May 2021).

27. Shinozaki, T.; Tomota, Y.; Fukino, T.; Suzuki, T. Microstructure evolution during reverse transformation of austenite from tempered martensite in low alloy steel. ISIJ Int. 2017, 57, 740-743. [CrossRef]

28. Barglik, J. Induction heating of small gear wheels in the contour hardening process. In Proceedings of the 19th International Symposium on Electromagnetic Fields in Mechatronics, Electrical and Electronic Engineering (ISEF 2019), Nancy, France, 29-31 August 2019; pp. 1-2.

29. Barglik, J.; Smalcerz, A.; Smagor, A.; Kopec, G. Experimental Stand for Investigation of Induction Hardening of Steel Elements. Metalurgija 2018, 57, 341-344.

30. Centre for Induction Technology. Fluxtrol 50. Available online: https://fluxtrol.com/inc/pdf/Fluxtrol-50-Specs.pdf (accessed on 15 May 2021).

31. Wróbel, T.; Przyszlak, N.; Dulska, A. Technology of Alloy Layers on Surface of Castings. Int. J. Met. 2019, 13, 604-610. [CrossRef] 